\title{
LA-UR-12-22920
}

Approved for public release; distribution is unlimited.

Title:

Author(s):

\section{Cameco UO3 Materials Analysis}

\author{
Hill, Mary Ann \\ Nolen, Blake Penfield \\ Wermer, Joseph R. \\ Wilkerson, Marianne P. \\ Fredenburg, David A. \\ Wagner, Gregory L. \\ Papin, Pallas A. \\ Scott, Brian L. \\ Guidry, Dennis Ray
}

Intended for:

Report for DOE

Report

Disclaimer:

Los Alamos National Laboratory, an affirmative action/equal opportunity employer,is operated by the Los Alamos National

Security, LLC for the National NuclearSecurity Administration of the U.S. Department of Energy under contract DE-AC52-06NA25396. By approving this article, the publisher recognizes that the U.S. Government retains nonexclusive, royalty-free license to publish or reproduce the published form of this contribution, or to allow others to do so, for U.S. Government purposes.

Los Alamos National Laboratory requests that the publisher identify this article as work performed under the auspices of the

U.S. Departmentof Energy. Los Alamos National Laboratory strongly supports academic freedom and a researcher's right to publish; as an institution, however, the Laboratory does not endorse the viewpoint of a publication or guarantee its technical correctness. 


\title{
Cameco $\mathrm{UO}_{3}$ Materials Analysis
}

Mary Ann Hill, Blake Nolen, Joe Wermer, Dennis Guidry, Pallas Papin, MST-6

Brian Scott, MPA-MC,

Marianne Wilkerson, C-NR

Gregory Wagner, C-PCS

Anthony Fredenburg, WX-9

\begin{abstract}
Uranium trioxide $\left(\mathrm{UO}_{3}\right)$ was characterized using a variety of techniques to better understand its physical properties. Scanning electron microscope (SEM) images were collected to examine particle morphology, which consisted of semi-spherical particles that tended to agglomerate before sonication. Particle size analysis revealed a singular mode distribution with a mean particle size of $43.0 \mu \mathrm{m}$. After sonication a bimodal distribution was produced with peak particle sizes at $0.226 \mu \mathrm{m}$ and $9.43 \mu \mathrm{m}$. The $\mathrm{O} / \mathrm{U}$ ratio was measured to be 3.09 by Cameco in 2009 , by gravimetric analysis. X-ray diffraction (XRD) showed that the sample was mostly $\gamma-\mathrm{UO}_{3}$ (87.1\%) with a small amount of $\mathrm{UO}_{3} \cdot 0.80 \mathrm{H}_{2} \mathrm{O}$ (12.9\%). Bulk and tap densities were determined to be $3.678 \pm 0.2$ and $4.81 \pm 0.2 \mathrm{~g} / \mathrm{cm}^{3}$, respectively (crystalline density is $7.3 \mathrm{~g} / \mathrm{cm}^{3}$ ). The stoichiometry was measured to be
\end{abstract}

\section{Introduction}

Uranium trioxide $\left(\mathrm{UO}_{3}\right)$, the hexavalent oxide of uranium, is also called uranyl oxide, uranium (VI) oxide, and uranic oxide. The generation of uranium trioxide is used industrially in the reprocessing of nuclear fuel and uranium enrichment. The $\mathrm{Cameco}^{\mathrm{U} O} \mathrm{O}_{3}$ production is shown in Figure 1. After the $\mathrm{U}_{3} \mathrm{O}_{8}$ has been concentrated from the ore, it is referred to as "yellow cake" which is impure $\mathrm{U}_{3} \mathrm{O}_{8}$. The impurities which exist in the uranium ore are heavy metals and daughter radioisotope decay products such as thorium, protactinium, and bismuth. To refine this material to pure $\mathrm{U}_{3} \mathrm{O}_{8}$, the impure $\mathrm{U}_{3} \mathrm{O}_{8}$ is first dissoved in nitric acid (shown in step 1):

$$
\mathrm{U}_{3} \mathrm{O}_{8}+8 \mathrm{HNO}_{3} \rightarrow 3 \mathrm{UO}_{2}\left(\mathrm{NO}_{3}\right)_{2}+2 \mathrm{NO}_{2}+4 \mathrm{H}_{2} \mathrm{O}
$$

This is accomplished in a two tank cascade system using large digestion tanks [2]. After digestion, the uranium in the impure uranyl nitric hexahydrate solution (UNH) is extracted using a two phase solvent extraction with tributylphosphate (TBP), an organic solvent which is 
suspended in a saturated hydrocarbon diluent (ISOPAR $\mathrm{M}^{\circledR}$ ). The solvent extraction process depends on association between the uranyl and nitrate ions to produce a neutral complex, step 2:

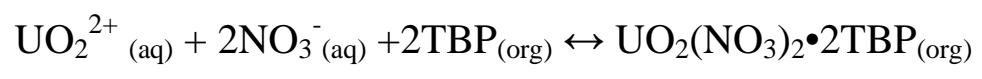

The purified uranium is stripped from the organic solvent phase with water, which produces a pure UNH solution, step 3. The UNH solution is then evaporated in a three stage evaporator. The product is molten $\mathrm{UNH}$, which is then denitrated to $\mathrm{UO}_{3}$ using cracked ammonia, in a stirred heavy walled semi-spherical reactor vessel. This process is run at $280^{\circ} \mathrm{C}$, which produces $\mathrm{UO}_{3}$ :

$$
\mathrm{UO}_{2}\left(\mathrm{NO}_{3}\right)_{2} \cdot 6 \mathrm{H}_{2} \mathrm{O} \rightarrow \mathrm{UO}_{3}+\mathrm{NO}_{2}+\mathrm{NO}+\mathrm{O}_{2}+6 \mathrm{H}_{2} \mathrm{O}_{(\mathrm{g})}
$$

There are seven polycrystalline polymorphs of $\mathrm{UO}_{3}$ since the uranium atom can be coordinated to six, seven, or eight oxygen atoms. There is an amorphous $\mathrm{UO}_{3}$ modification also. The most thermodynamically stable form of $\mathrm{UO}_{3}$ is $\gamma-\mathrm{UO}_{3}$. At $373 \mathrm{~K}$ it is a tetragonal structure, while at $293 \mathrm{~K}$ the structure is orthorhombic.

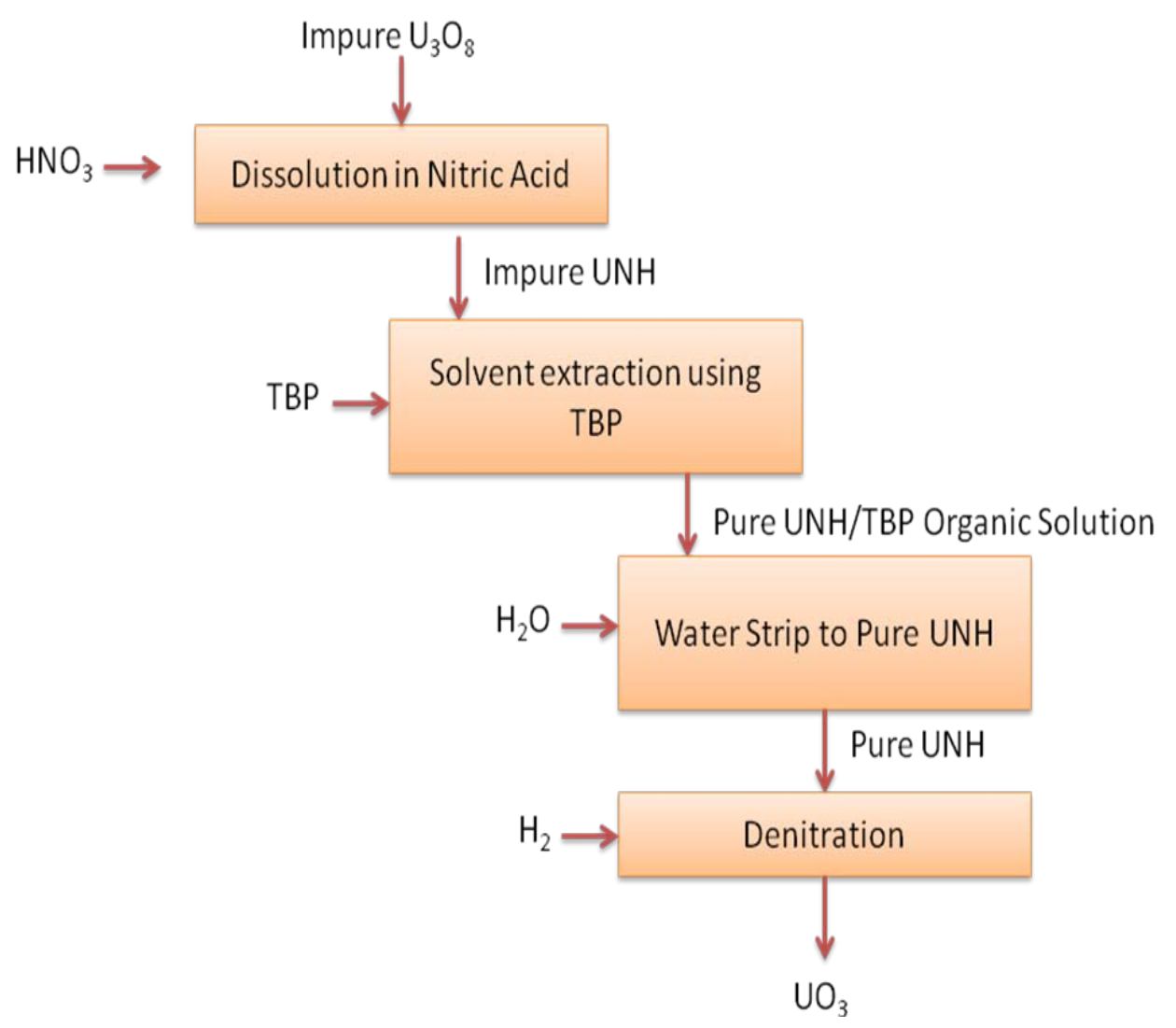

Figure 1: Cameco UO3 Fabrication [2]. 


\section{Material Analysis Techniques}

To determine the powder morphology, SEM images were taken of a small powder sample. Along with morphology, SEM images were compared with laser scattering particle size measurements which is best used for analyzing spherical particles, unlike the Cameco oxide particles. The SEM samples were prepared by using carbon tape on a flat SEM mount, and a very small amount of $\mathrm{UO}_{3}$ was sprinkled on top of the carbon tape and dusted with canned air to remove loose material from the stub. A FEI DB-235 dual-beam FIB/SEM (focused ion beam) was employed to collect the SEM images.

Light scattering from solution suspension of particles was used to determine the size distribution of the oxides in both the as-received state and after sonication. A Horiba Laser Scattering Analyzer, Model LA950, was utilized. Approximately 0.2-0.5 g of $\mathrm{UO}_{3}$ powder was suspended in ethylene glycol, which was subsequently pumped through the Horiba instrument. Particle size was measured before sonication and then remeasured at 1 to 2 minute intervals during sonication up to 16 minutes.

The particulates were analyzed for surface area using the Brunauer-Emmet-Teller (BET) method. The surface area determined by the BET method includes the surface of interior surface-connected pores. $\mathrm{A} \mathrm{UO}_{3}$ sample was placed in a quartz sample vessel attached to a Quantachrome Autosorb, Model 1 MP instrument. The sample was dynamically pumped while heating to $200^{\circ} \mathrm{C}$ for 2 hours, followed by 2 hours of further pumping. Nitrogen absorption was used to determine the surface oxide of each oxide.

Chemical stoichiometry of the oxides was also investigated using gravimetric analysis of the oxide in a reducing environment at $800^{\circ} \mathrm{C}$. Current and historical measurements have been made by LANL and the manufacturer, Cameco, respectively.

X-Ray diffraction (XRD) measurements were made from 0.05 g powder samples. Lattice parameters have been calculated and compared to literature values [3].

Both bulk and tap densities were calcualted using a Quantachrome Autotap, 02106-60-1 tap density machine. A $25 \mathrm{~mL}$ graduated cylinder with $0.2 \mathrm{~mL}$ increments was loaded with roughly 40 grams of $\mathrm{UO}_{3}$. The initial mass and volumetric measurments were made and the bulk density was calculated. The material was then tapped 3000 times, and the final volume measured to calculate the tap density. 


\section{Results}

\section{Particle Morphology and Size Distribution}

Particle shape and size are primary powder characteristics that influence the flow rate, apparent density, compressibility, and sinterability. Characterization of powder particles to be used in powder metallurgy processing is important because particle morphology can have a significant effect on final material properties. The particle morphology was determined to be semisphereical and irregular in shape as shown in Figure 2. The irregular shape promotes interlocking of particles which may promote greater green strength. Upon examination at higher magnifications, it becomes evident that the small spherical shaped particles show little coalescence (Figures 3 and 4).
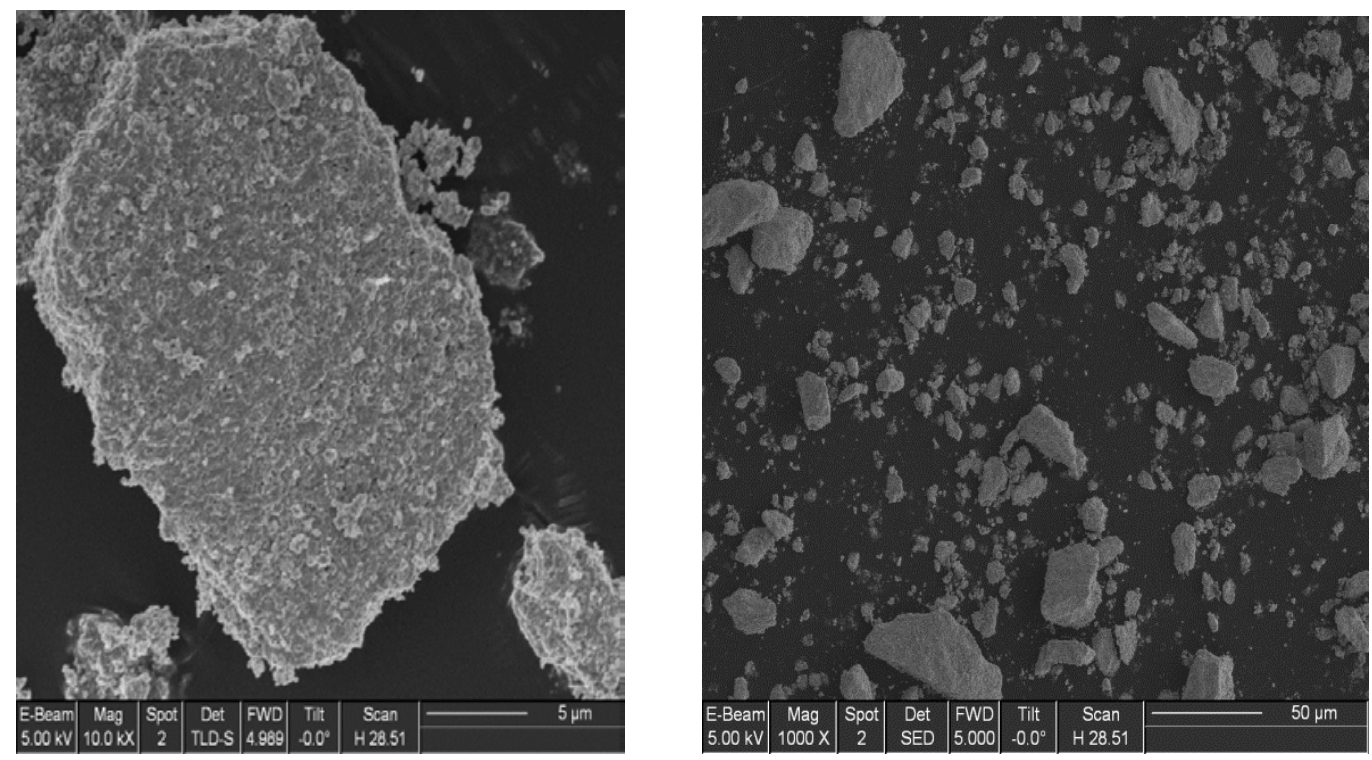

Figure 2. Irregularly shaped $\mathrm{UO}_{3}$ particles. Small spherical shaped particles are noted on the surface of the particle in the image on the left. Bimodal size distribution is evident from the image on the right. 


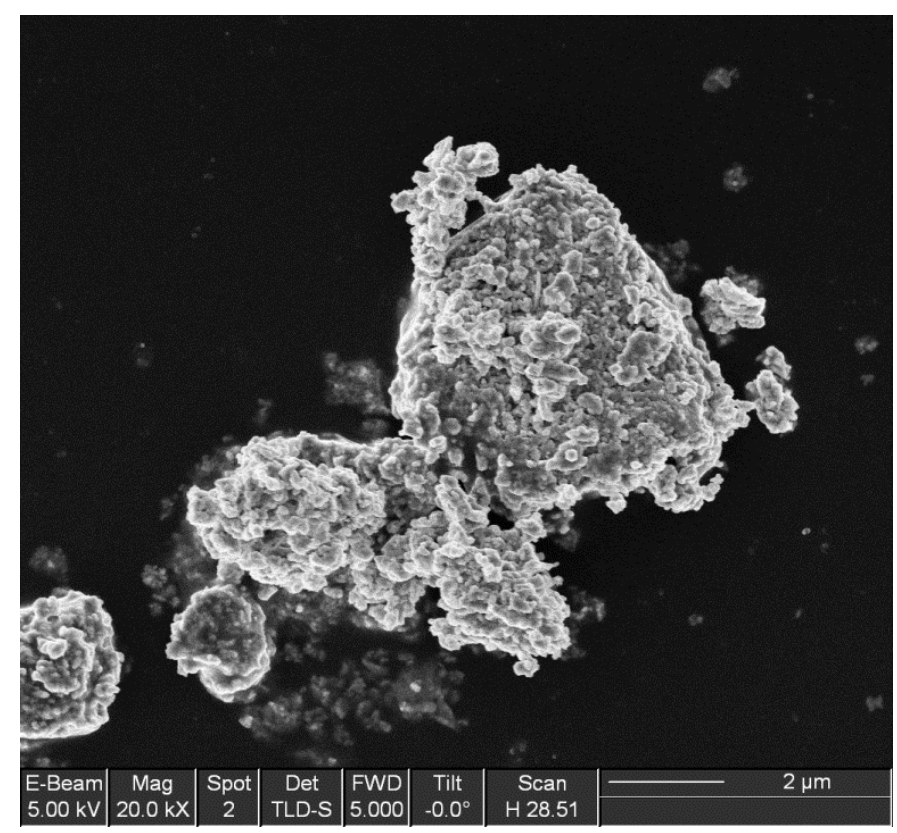

Figure 3: At higher magnification an aggregate of small spherical particles exhibiting little coalescence is observed.

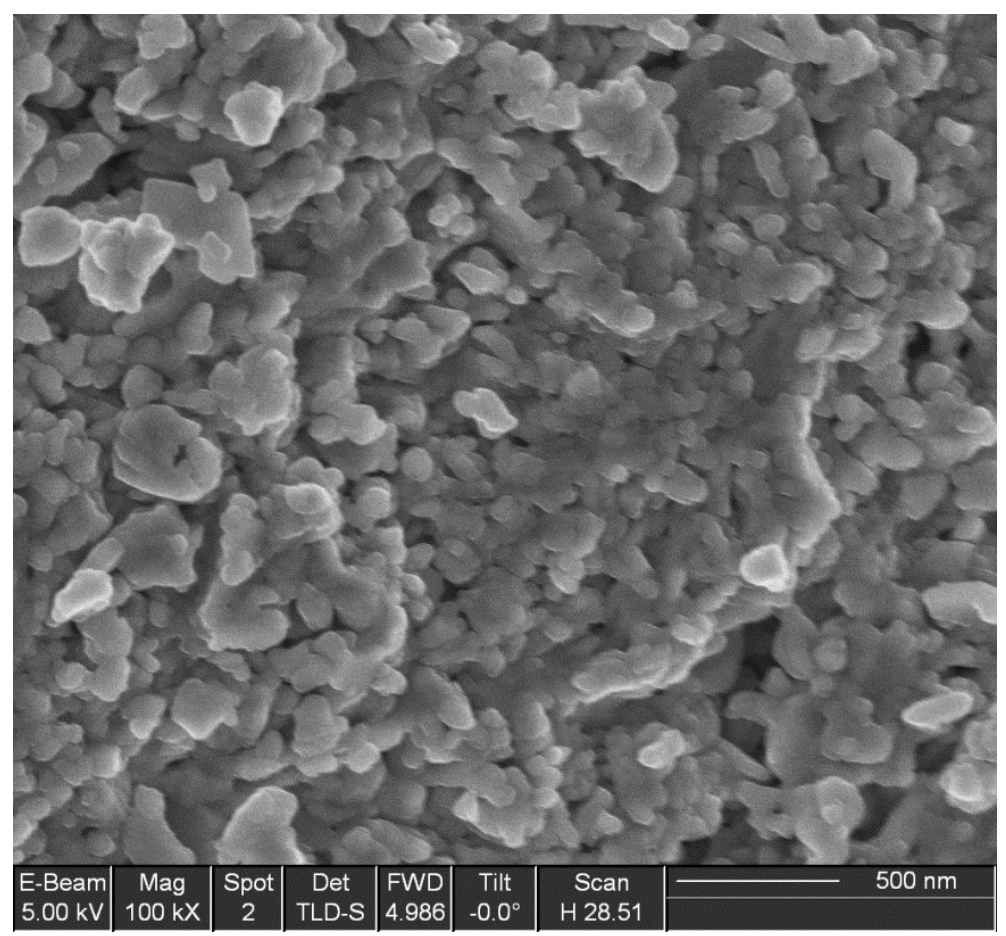

Figure 4: Surface of aggregate particle at high magnification.

At lower magnification, it is observed that the $\mathrm{UO}_{3}$ particles do not agglomerate as extensively as the $\mathrm{U}_{3} \mathrm{O}_{8}$ particles, shown in Figure 5 [4]. When a small amount of force is applied 
to these large single particles, they appear to fracture. The $\mathrm{UO}_{3}$ particle size decreased substantially following sonication, comparable to the Cameco $\mathrm{U}_{3} \mathrm{O}_{8}$ analysis [4]. However, the $\mathrm{U}_{3} \mathrm{O}_{8}$ exhibited a larger maximum particle size due to its tendency to agglomerate. As can be seen in Table 1 , the large $\mathrm{UO}_{3}$ single particles fragment with sonication. The average $\mathrm{UO}_{3}$ particle size prior to sonication is 43 microns exhibiting a singular mode distribution. The sonication fractures the large particles into smaller particles, which results in a final bimodal distribution. This fracturing can be seen graphically in Figure 6, which compares the 1+ distribution corresponding to the as-received material to that of the final sonicated material.
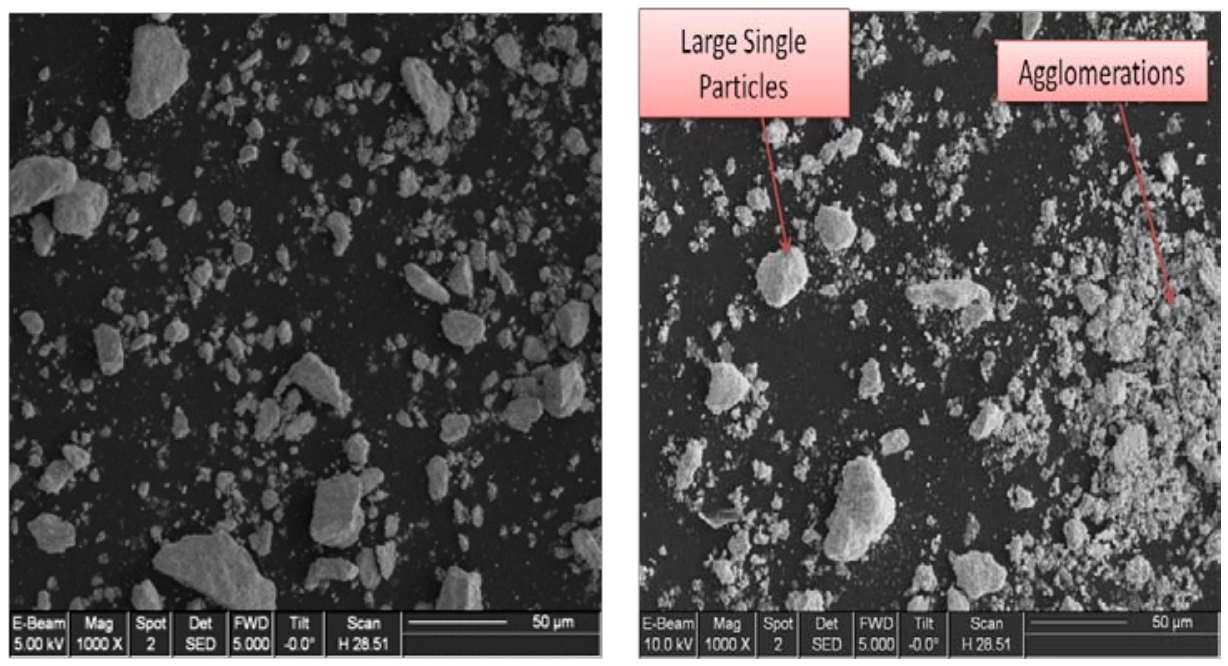

Figure 5: SEM images showing morphology and lack of agglomeration of $\mathrm{UO}_{3}$ (left image) compared to the Cameco $\mathrm{U}_{3} \mathrm{O}_{8}$ (right image).

Table 1: Particle Size at different sonication times.

\begin{tabular}{|c|c|c|c|}
\hline Material & $\begin{array}{c}\text { Sonication } \\
\text { Time } \\
\text { (min.) }\end{array}$ & Modes & $\begin{array}{c}\text { Mean } \\
(\mu \mathrm{m})\end{array}$ \\
\hline UO3 & $\begin{array}{c}\text { As- } \\
\text { Received }\end{array}$ & $1+$ & 43 \\
\cline { 2 - 4 } & 0.5 & 2 & 24.8 \\
\cline { 2 - 4 } & 1 & 2 & 20.6 \\
\hline
\end{tabular}




\begin{tabular}{|c|c|c|c|}
\hline \multirow{10}{*}{} & 2 & 2 & 17.8 \\
\cline { 2 - 4 } & 3 & 2 & 15 \\
\cline { 2 - 4 } & 5 & 2 & 11.8 \\
\cline { 2 - 4 } & 7 & 2 & 11.1 \\
\cline { 2 - 4 } & 10 & 2 & 8.24 \\
\cline { 2 - 4 } & 13 & 2 & 7.61 \\
\hline
\end{tabular}

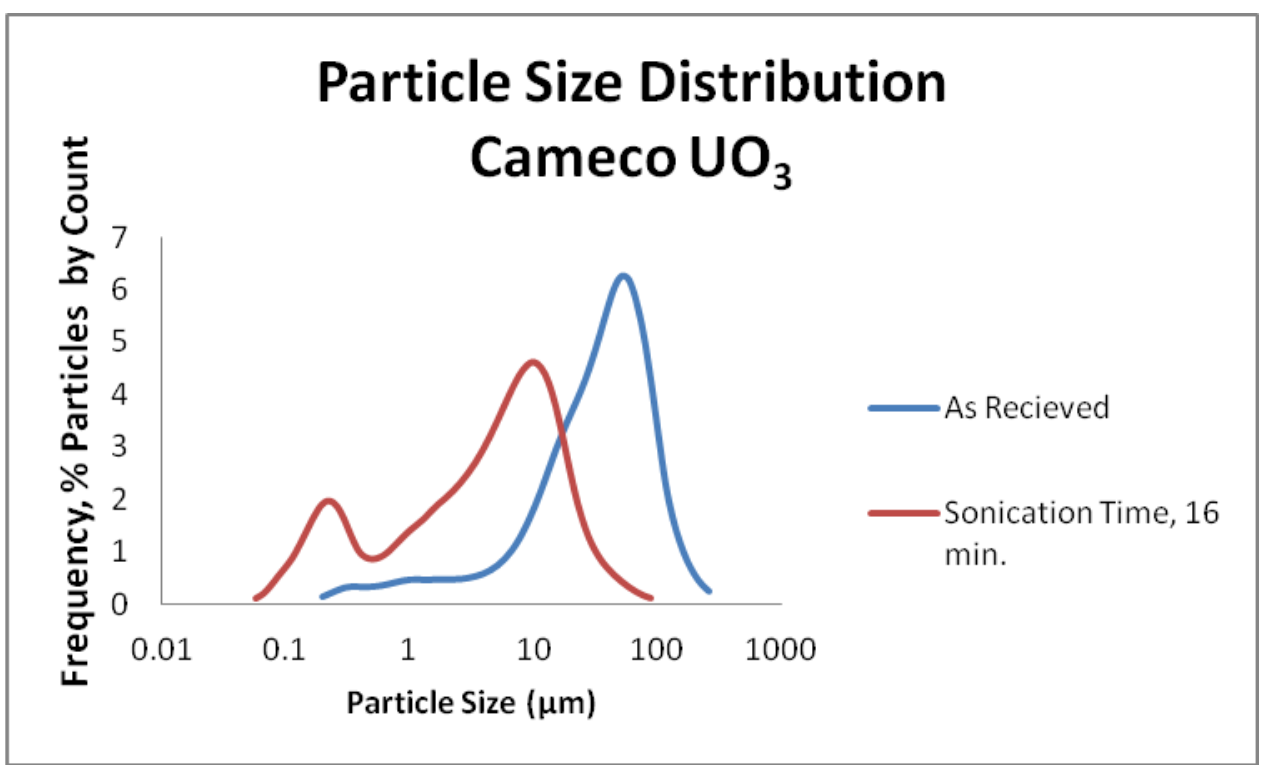

Figure 7: Particle Size Distribution

The mean of the distribution is 7.60 microns, at long sonication times (16 minutes). The small agglomeration effect and fracture effect is seen initially as a singular mode distribution of the asreceived material and a mean particle size of 43.0 microns, then dramatically reducing in mean size to 0.226 microns and 9.43 microns for the bimodal distribution after sonication. This agglomeration is due to the surface area of the small particles.

\section{Surface Area}

Surface area measurements are helpful in understanding sintering behavior and surface reactivity. The average surface area of the as-received material was $0.9723 \mathrm{~m}^{2} / \mathrm{g}$. The surface area is expected to be larger for a sonicated sample, due to the reduction in particle size. The 
agglomeration is caused by Van der Waals forces, which increase as the surface area increases and the particle size decreases.

\section{Bulk and Tap Densities}

Density aids in distinguishing between different materials and the determination of inaccessible porosity of a powder. For free-flowing powders, there is usually little difference between the bulk and tap densities. For poorer flowing powder, there is a greater propensity for interparticle interactions and a greater difference between the bulk and tap densities will be observed. Bulk and tap densities were measured to be $3.678 \pm 0.2$ and $4.81 \pm 0.2$ g/cc, respectively.

\section{$\underline{\text { X-Ray Diffraction }}$}

$\mathrm{X}$-Ray diffraction data of the $\mathrm{UO}_{3}$ powder was fitted to the corresponding lattice parameters from literature and graphed, as shown in Figure 8. It revealed mostly $\gamma-\mathrm{UO}_{3}(87.1 \%)$ and a small amount of $\mathrm{UO}_{3} \cdot 0.80 \mathrm{H}_{2} \mathrm{O}(12.9 \%)$.

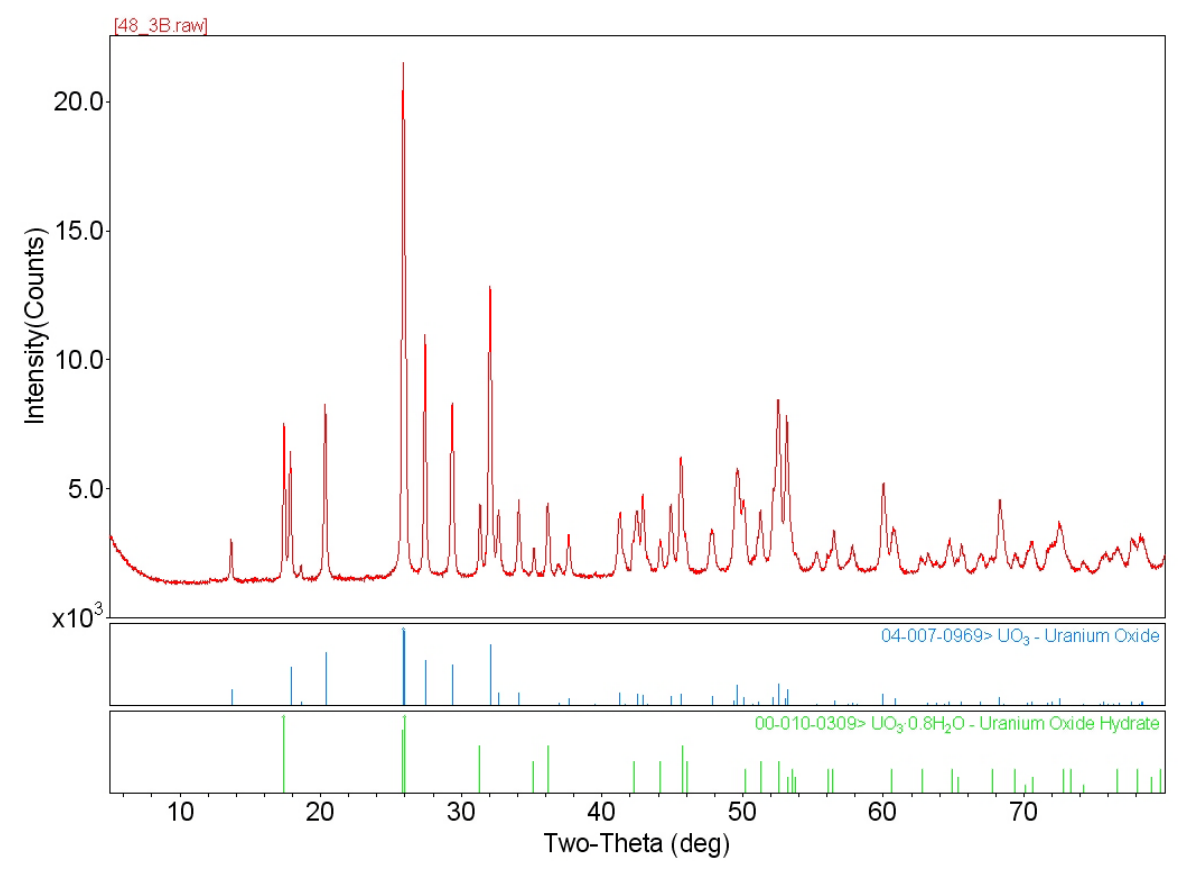

Figure 8. X-Ray Diffraction spectrum of Cameco $\mathrm{UO}_{3}$. Blue peaks represent $\mathrm{UO}_{3}$ while green peaks are $\mathrm{UO}_{3} \bullet 0.8 \mathrm{H}_{2} \mathrm{O}$. 


\section{Stoichiometry}

The O/U Ratio

The O/U ratio or Stoichiometry was measured to be 2.99, in 2012. Cameco analyzed the material in December 2009, using a similar technique and at that time the O/U ratio was 3.08. This slight change over 3 years is expected due to being stored in a Nalgene bottle packed under standard atmospheric conditions of 1 atmosphere air, with a humidity level of 40\%. Thermodynamically the $\mathrm{UO}_{3}$ will reduce to a final $2.6774 \mathrm{O} / \mathrm{U}$ ratio corresponding to $\mathrm{U}_{3} \mathrm{O}_{8}$ [1].

\section{Acknowledgement}

The authors would like to thank David Robbins, Darcie Dennice-Koller, and Mark Paffett for their support of this work.

\section{References}

1. M. Benedict, T. H. Pigford, and H. W. Levi, Nuclear Chemical Engineering, $2^{\text {nd }}$ edition, McGraw-Hill, New York, 1981, p. 269.

2. A. W. Ashbrook, The Refining and Conversion of Uranium Yellowcake to Uranium Dioxide and Uranium Hexafluoride Fuels in Canada: Current Process, in Advances in Uranium Refining and Conversion 1987, IAEA: Vienna, Austria, p. 9-20.

3. Data, ICFD, Powder Diffraction Data, PDF-4+, Editor 2010, International Center for Diffraction Data: Newton Square, PA.

4. B. P. Nolen, J. R. Wermer, D. R. Guidry, P. A. Papin, D. A. Fredenburg, M. P. Wilkerson, B. L. Scott, and G. L. Wagner, Cameco $U_{3} O_{8}$ Materials Analysis, Los Alamos National Laboratory, LA-UR-12-21032.

5. B. P. Nolen, J. R. Wermer, D. R. Guidry, P. A. Papin, D. A. Fredenburg, M. P. Wilkerson, B. L. Scott, and G. L. Wagner, Investigation of the Effects of Material and Chemical Properties of Two Different Supply Stocks of $\mathrm{UO}_{2}$ for Nuclear Fuel, Los Alamos National Laboratory, in progress. 
